\title{
Summary of NIST/GSA Workshop on Application of Seismic Rehabilitation Technologies to Mitigate Blast-Induced Progressive Collapse September 10, 2001 Oakland, CA
}

Editors

Nicholas J. Carino

H.S. Lew

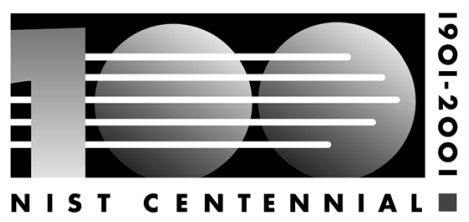

National Institute of Standards and Technology Technology Administration, U.S. Department of Commerce 



\section{Summary of NIST/GSA Workshop on Application of Seismic Rehabilitation Technologies to Mitigate Blast- Induced Progressive Collapse September 10, 2001 Oakland, CA}

Editors

Nicholas J. Carino

H.S. Lew

Structures Division Building and Fire Research Laboratory

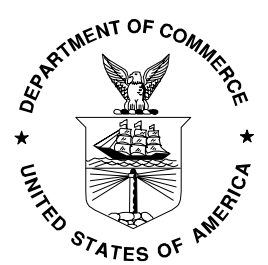

U.S. Department of Commerce Donald L. Evans, Secretary

Technology Administration Phillip J. Bond, Under Secretary for Technology

National Institute of Standards and Technology Arden L. Bement, Jr., Director 



\begin{abstract}
On September 10, 2001 an informal workshop was held in Oakland, California to discuss the applicability of seismic rehabilitation technologies to enhance the resistance of buildings to progressive collapse in the event of loss of primary load-carrying elements. The workshop was organized by the Building and Fire Research Laboratory with support from the General Services Administration. The workshop included short presentations by invited experts in the areas of blast resistance and seismic rehabilitation. The presentations were followed by an open discussion of what needs to be done to speed up the development of consensus standards that can be used by practitioners for design of new buildings and rehabilitation of existing buildings for resistance to progressive collapse. The workshop concluded that there is a need to review available knowledge on blast resistant design and progressive collapse and develop a national plan to accelerate the development of needed standards. This report summarizes the workshop discussions and outlines an action plan.
\end{abstract}

Keywords: Building technology; blast resistance; progressive collapse; seismic rehabilitation. 


\section{TABLE OF CONTENTS}

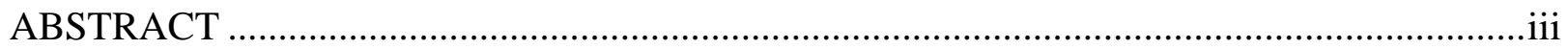

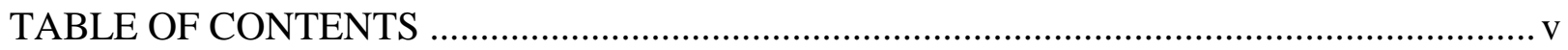

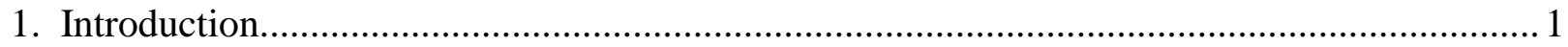

2. Comparisons of Seismic and Blast Loading (E. Hinman) ……............................................ 3

3. Example of Seismic Strengthening Technology Applied to Blast Resistance (F. Seible)........5

4. Seismic Rehabilitation Philosophies (R. Hamburger) ………………………………............ 7

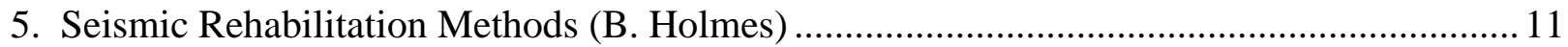

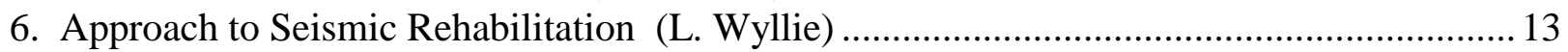

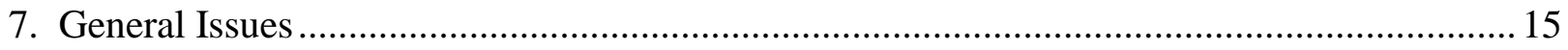

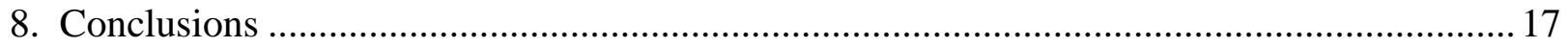




\section{Introduction}

As was made evident by the September 11, 2001 collapse of the twin towers of the World Trade Center (WTC) in New York City, progressive collapse after a terrorist act is a leading cause of death and destruction. While the WTC event is extraordinary, ground level explosive threats are more likely to occur (Fig. 1). There are literally thousands of federal facilities that are prone to catastrophic collapse initiated by the loss of a few structural members. Progressive collapse may occur immediately upon loss of primary structural members. If fire is present, however, the collapse may be delayed to a later time as the structural capacities of the remaining members are compromised during fire exposure. The latter scenario is believed to be the case in the collapse of the WTC towers. There is an urgent national need to develop design standards and practicable technologies to retrofit existing facilities to enhance blast resistance and mitigate the likelihood of progressive collapse in case of localized structural damage followed by fire.

There is a belief within the structural engineering community that some of the technologies that have been developed for seismic strengthening may be applicable to mitigate progressive collapse due to blast loading. Although seismic loading is in many ways different from blast loading, it is postulated that the same principles of "toughening" that are used to enhance seismic resistance of structural members may provide adequate blast protection either by preventing blast-induced failure of structural members or provide alternative load paths to prevent progressive collapse.

With support from the General Services Administration (GSA), an informal workshop was organized by the Structures Division of the Building and Fire Research Laboratory to bring together a small group of experts to discuss this issue. Coincidentally, the workshop was held one-day before the twin towers of the World Trade Center were destroyed.

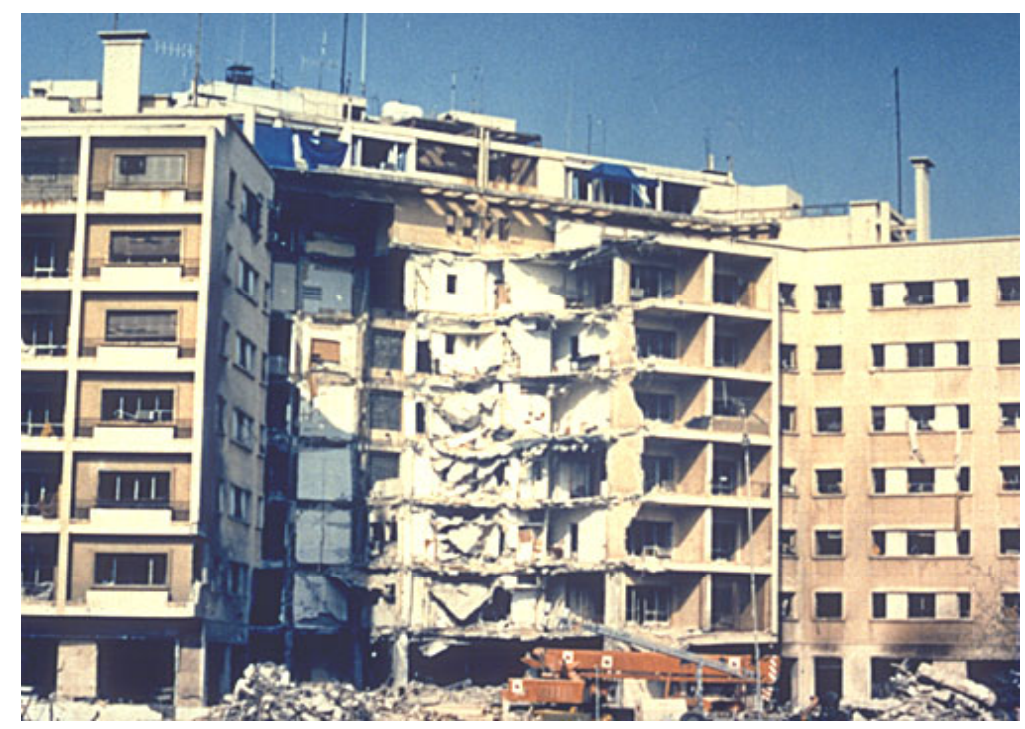

Fig. 1- Example of progressive collapse initiated by ground level blast loading. 
The workshop participants were as follows:

Nick Carino, NIST

Ron Hamburger, ABS Consulting (EQE Structural Engineers Division)

Eve Hinman, Hinman Consulting Engineers

Bill Holmes, Rutherford and Chekene Consultants

H.S. Lew, NIST

Bela Palfalvi, GSA

Frieder Seible, University of California, San Diego

Young Sohn, DTRA/TDACS

Loring Wyllie, Degenkolb Engineers

The participants were asked to address the following questions:

- Can seismic strengthening methods for concrete and masonry members be applied to strengthening of members (both horizontal and vertical members) to resist blast loading?

- Are there adequate data on the behavior of seismically strengthened members (compression and flexural members)?

- Can we use available seismic strengthening data directly for blast load applications or do we need additional data to bridge between seismic and blast load applications?

- De we need to generate data exclusively for blast loading?

Workshop participants were asked to make brief presentations on the following topics:

- Summary of differences between seismic and blast loading and failure modes of structures;

- Summary of seismic strengthening philosophies;

- Summary of seismic strengthening technologies.

Following these brief presentations, workshop participants engaged in a general discussion of how the engineering profession should proceed on the subject of progressive collapse mitigation and blast-resistant design in general. This report summarizes the discussion points of the workshop. 


\section{Comparisons of Seismic and Blast Loading (E. Hinman)}

Similarities between seismic and blast loading include the following:

- Dynamic loads and dynamic structural response;

- Involve inelastic structural response;

- Focus on life safety as opposed to preventing structural damage;

- Nonstructural damage and hazards;

- Similar "buzzwords": performance based design; life safety issues; progressive collapse; structural integrity; ductility, continuity, and redundancy; balanced design.

Differences between these two types of loading include (see Fig. 2):

- Blast loading is due to a propagating pressure wave as opposed to ground shaking;

- Blast results in direct pressure loading to structure; pressure is in all directions, whereas a seismic event is dominated by lateral load effects;

- Blast loading is of higher amplitude and very short duration compared with a seismic event;

- Magnitude of blast loading is difficult to predict and not based on geographical location;

- Blast effects are confined to structures in the immediate vicinity of event because pressure decays rapidly with distance; local versus regional event;

- Progressive collapse is the most serious consequence of blast loading;

- Slab failure is typical in blasts due to large surface area an upward pressure not considered in gravity design;

- Small database on blast effects on structures;

- Seismic-resistant design is mature compared with blast-resistant design.

In summary, while the effect of blast loading is localized compared with an earthquake, the ability to sustain local damage without total collapse (structural integrity) is a key similarity between seismic-resistant and blast-resistant design. 
Blast Loading

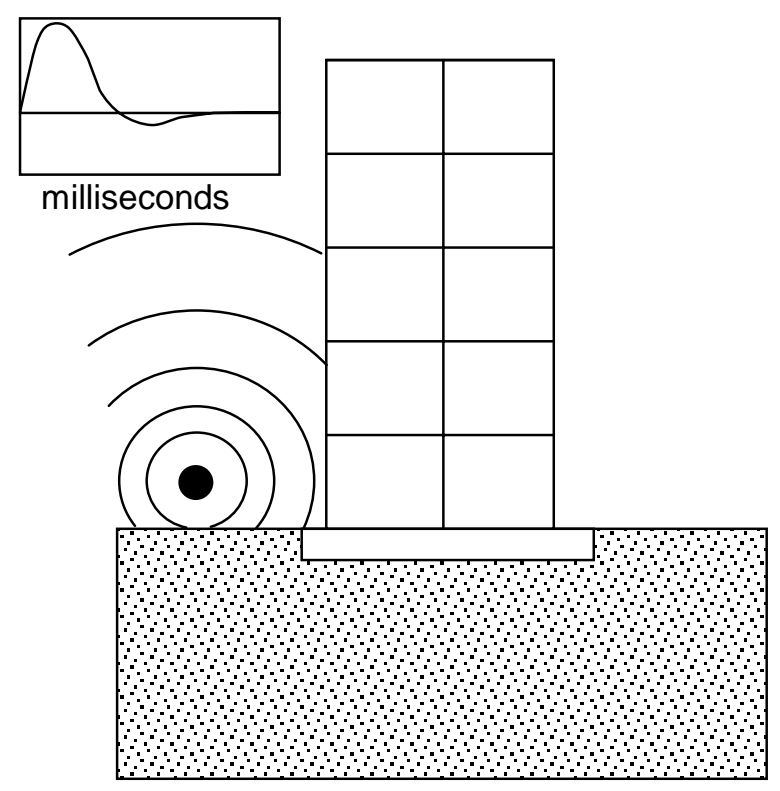

Short duration, high amplitude above ground pressure pulse

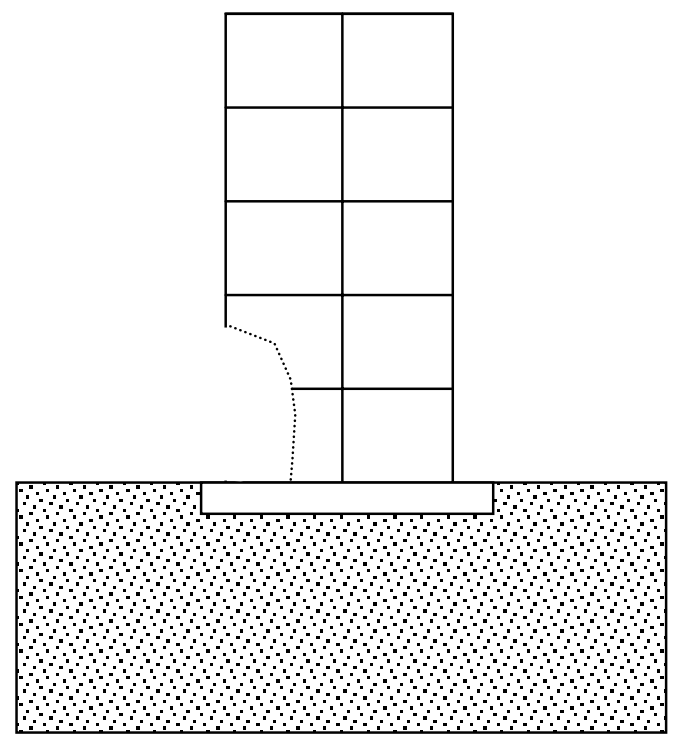

Localized response
Seismic Loading

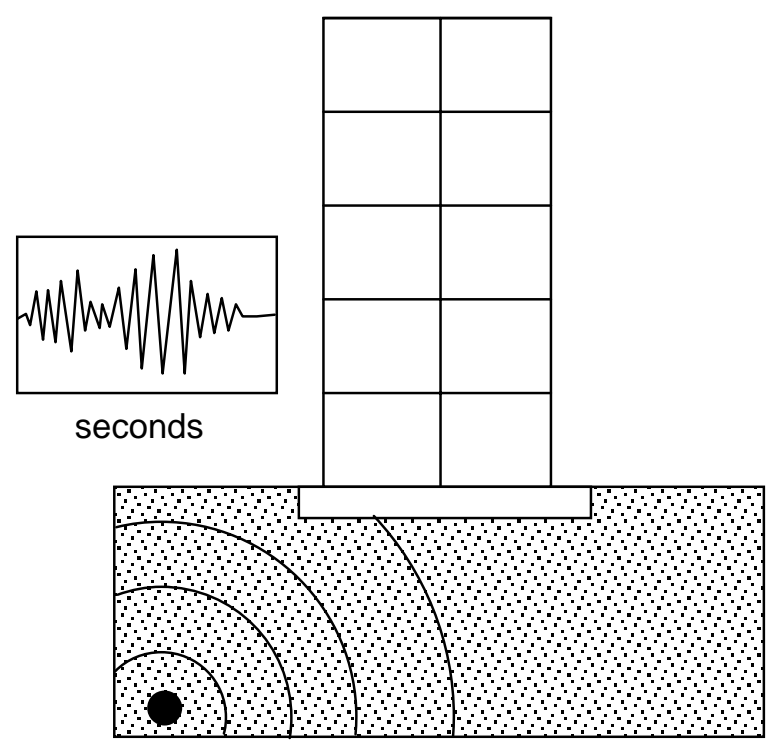

Long duration ground shaking

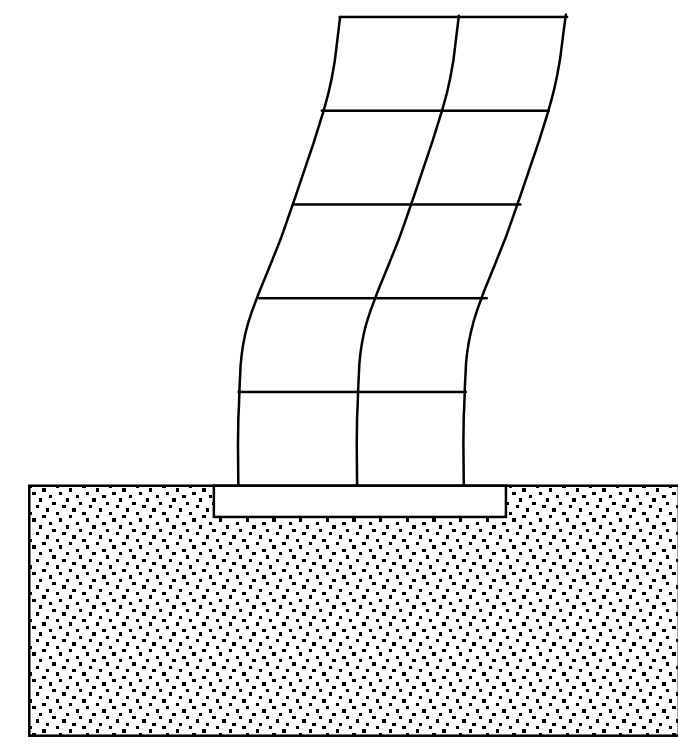

Global response

Fig. 2- Comparison of blast and seismic loading (top) and the structural response (bottom) 


\section{Example of Seismic Strengthening Technology Applied to Blast Resistance (F. Seible)}

The University of California, San Diego (UCSD) is investigating the use of carbon fiber reinforced polymers (FRP) to strengthen columns to resist the direct effects of blast loading. Walls and floors are also being considered for future study. Greater volume of FRP is used than for seismic strengthening. UCSD is carrying out full-scale component tests as part of a reinforced concrete retrofit program being conducted by Karagozian \& Case Structural Engineers for Defense Threat Reduction Agency (DTRA). Quasi-static tests are conducted at UCSD and field blast-load tests are conducted at DTRA Operations in Albuquerque, New Mexico (see Fig. 3). Quasi-static tests resulted in similar failure modes as observed in blast tests (brittle shear failure at ends and flexural failure of middle portion). There is collaboration with the Technion University in Israel.

Blast loading is characterized by a high-pressure pulse (up to $10,000 \mathrm{psi}$ [70 $\mathrm{MPa}$ ] for 10 to 15 $\mathrm{ms}$ ) followed by a small negative pressure. A high-speed hydraulic testing apparatus is being proposed to simulate blast loading and reduce the need of having to use explosives to test structural elements.
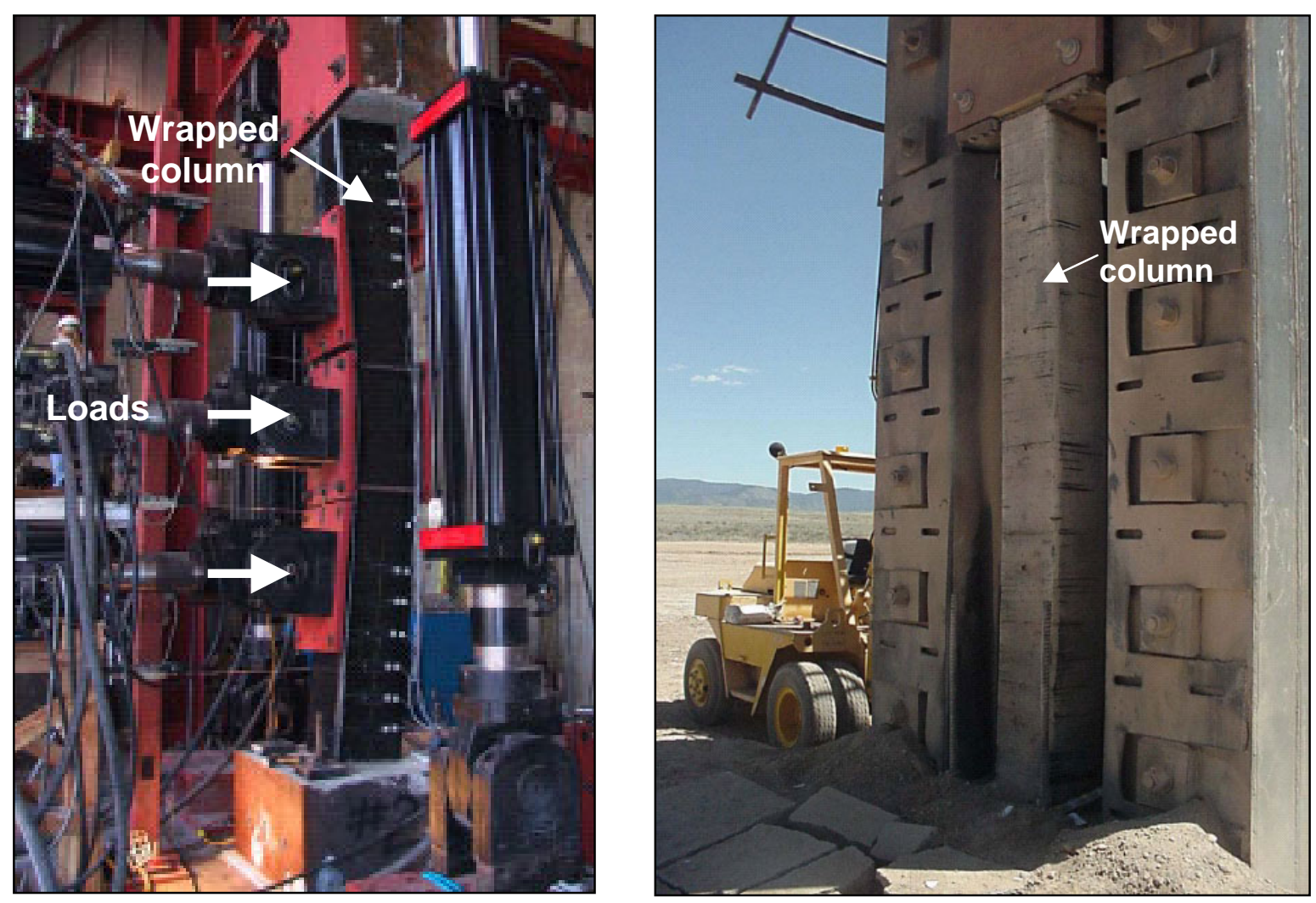

Fig. 3-(Left) Quasi-static tests of carbon FRP wrapped reinforced concrete column; (right) appearance of wrapped column after blast test 


\section{Seismic Rehabilitation Philosophies (R. Hamburger)}

Inadequately tied structural elements are a major reason for seismic retrofit work. Providing continuity is one aspect of seismic retrofit methods, and these may provide collateral benefit with regard to mitigating progressive collapse.

The base shear versus lateral displacement (drift) relationship (pushover curve) summarizes the lateral response of a structure, and level of damage is related to position on the curve as shown in Fig. 4.

The ATC 40 document ("Seismic Evaluation and Retrofit of Concrete Buildings") introduced the "capacity spectrum technique" as a way to conceptualize the effects of different retrofit strategies for concrete buildings. Figure 5 represents the elastic response spectrum of single degree of freedom structure during a given earthquake. For a given period, this "demand" spectrum gives the maximum base shear and lateral drift. The presence of damping (energy dissipation mechanisms) reduces the maximum base shear and drift. In the "capacity spectrum technique" the demand spectrum and the capacity curve are overlaid and their intersection represents the expected response of the structure for a given earthquake. If the capacity curve does not intersect the demand spectrum (the dotted curve in Fig. 6), the structure would be predicted to collapse during the given earthquake. By using this technique, it is easy to explain the basis for different seismic retrofit methods.

Seismic strengthening methods can be divided into the following categories:

\begin{tabular}{|l|l|}
\hline \multicolumn{1}{|c|}{ Method } & \multicolumn{1}{c|}{ Basis } \\
\hline Strengthening & Increase the base shear capacity \\
\hline Stiffening & $\begin{array}{l}\text { Increase base shear required to produce a given drift (less } \\
\text { effective method than strengthening) }\end{array}$ \\
\hline Stiffening and strengthening & Most common method to increase base shear capacity \\
\hline Base isolation & $\begin{array}{l}\text { Essentially reduces stiffness of structure (or increases the } \\
\text { period) so that there is low base shear demand for given drift } \\
\text { level; while concentrating most drift demands in compliant } \\
\text { bearings capable of accommodating these drifts; very } \\
\text { effective and very expensive }\end{array}$ \\
\hline Energy dissipation & $\begin{array}{l}\text { Reduces the demand by increasing the effective damping of } \\
\text { the structure }\end{array}$ \\
\hline Increasing ductility & Increase the deformation capacity of the structure \\
\hline
\end{tabular}




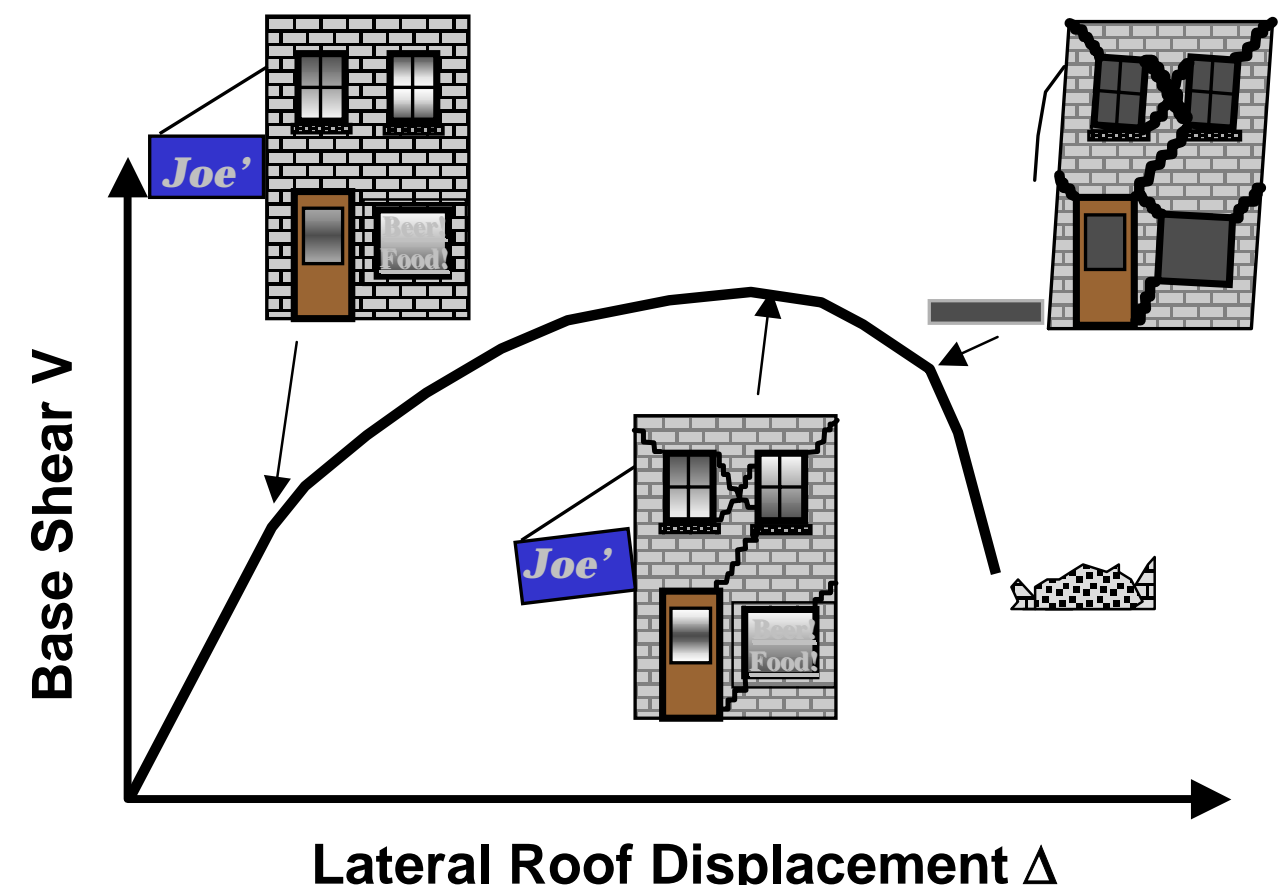

Fig. 4-Relationship between base shear-displacement curve of structure and damage state

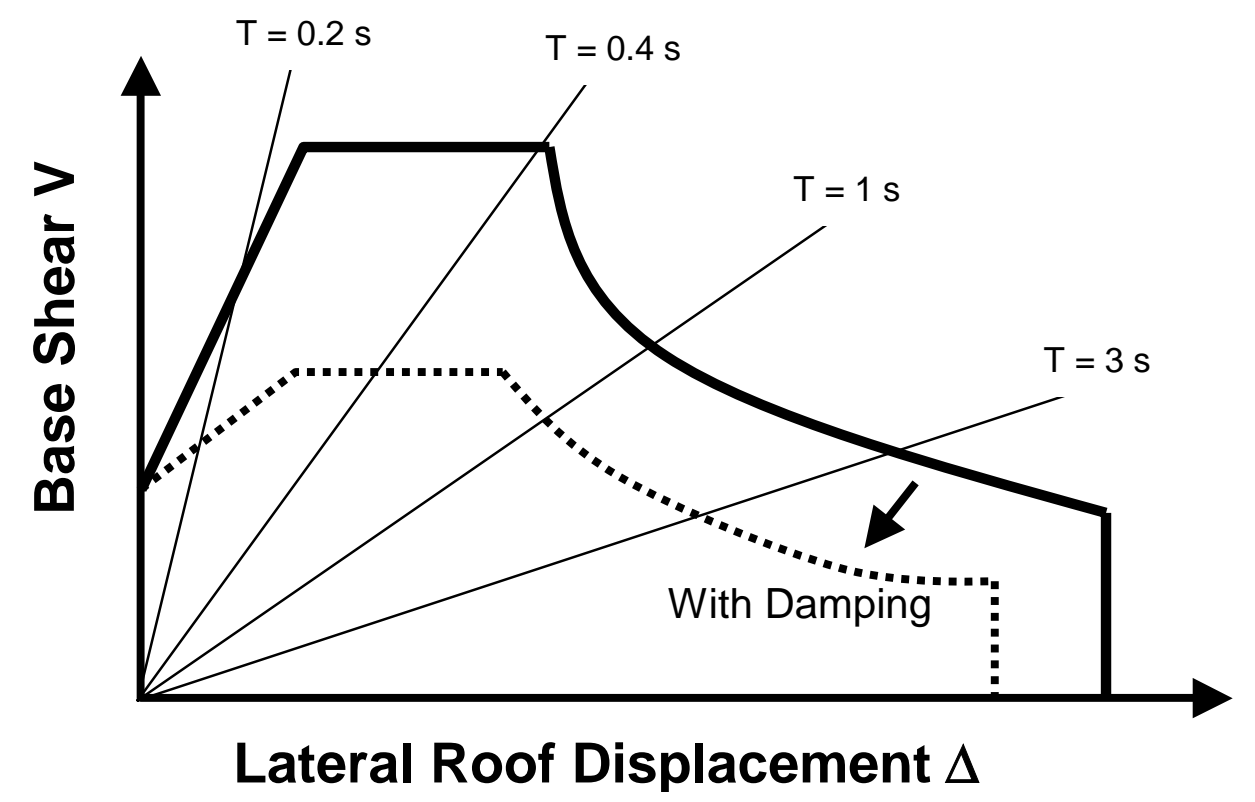

Fig. 5-Response spectrum showing maximum base shear and lateral drift as a function of period and damping 


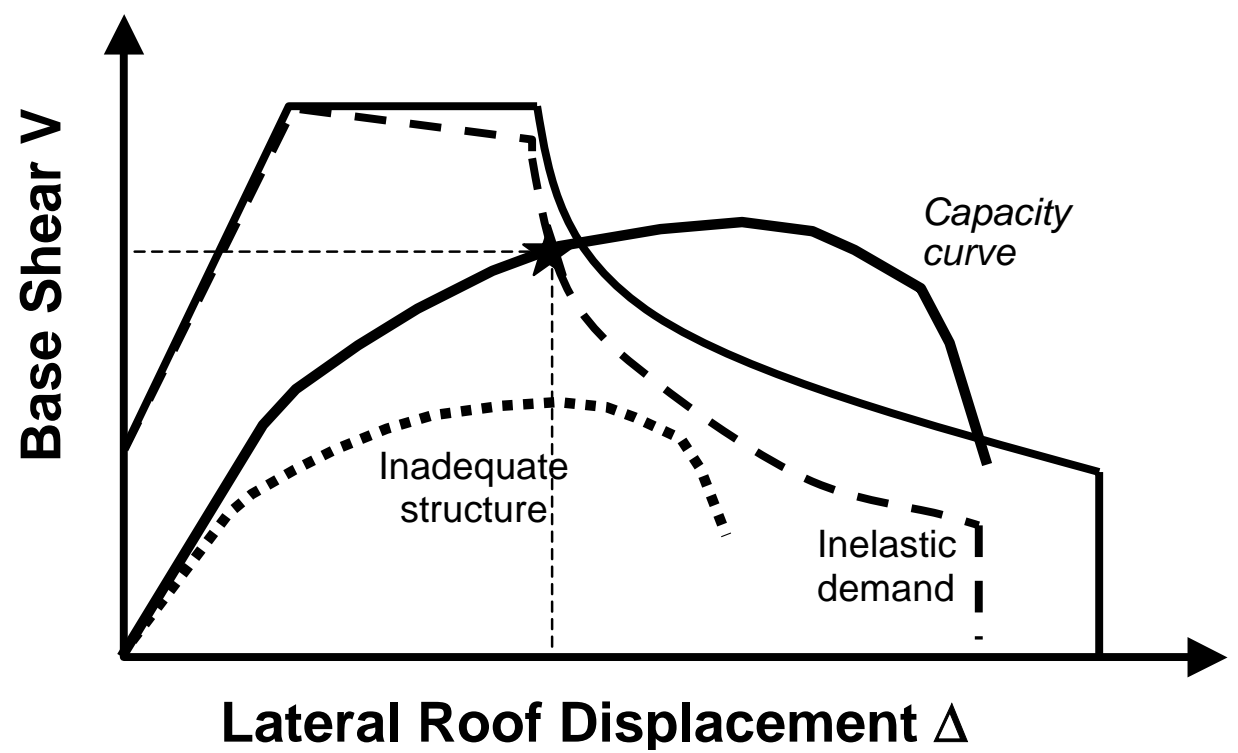

Fig. 6-In the capacity spectrum technique the capacity curve shown in Fig. 1 is superimposed on the inelastic demand spectrum; the intersection represents the expected response of the structure during the given earthquake, from which the damage state is estimated. The capacity curve of an inadequate structure lies totally below the demand spectrum. 


\section{Seismic Rehabilitation Methods (B. Holmes)}

There is no list or catalog of specific seismic rehabilitation techniques: a variety of systems and materials are used. The choice for a particular project is limited by the engineer's imagination and judgement.

There are non-technical issues that affect the technique or system that will be used:

- Seismic performance;

- Cost;

- Disruption to users;

- Effect on building use;

- Aesthetics, including historic "fabric"

The selected method is affected by the overall strategy of the rehabilitation, which can include the following:

- Connectivity (reducing falling hazards and providing alternative load paths);

- Modification of global behavior (usually decreases deformations during earthquake);

- Modification of local behavior (usually increases deformation capacity)

When a structural model is created, it is assumed that structural elements are connected properly to each other. Part of the rehabilitation should be to ensure that the assumed connectivity could in fact be realized. The load path has to be checked to ensure that all the connections involved in the transfer of load to the foundation have adequate capacity. The effects of the foundation stiffness must not be disregarded. Some of the actions to ensure adequate connectivity include:

- Tie falling hazards (walls) to the structure or remove them;

- Add steel or concrete collectors or ties to transmit load to lateral load resisting elements; strengthen diaphragms;

- Tie together precast elements;

- Enhance foundations or account for increased deformation at foundations.

Modification of global behavior may involve the following actions:

- Enhancing the global stiffness and strength of the structure to reduce deformations. This may be done by adding shear walls, moment frames, or braced frames. Deformation compatibility needs to be considered.

- Redistributing deformations by eliminating soft or weak stories or by eliminating tendency for torsion;

- Controlling the response by use of isolation, additional damping, or active control.

The local behavior of structural elements may be improved by actions such as:

- Increasing strength or deformation capacity; for example, providing confinement of concrete, adding external shear capacity; providing additional tension reinforcement;

- Improving the dynamic response by localized reduction of strength or stiffness, for example, convert from brittle shear strength-controlled failure to ductile moment-controlled failure;

- Adding a reliable gravity load support system (confining concrete columns or adding 

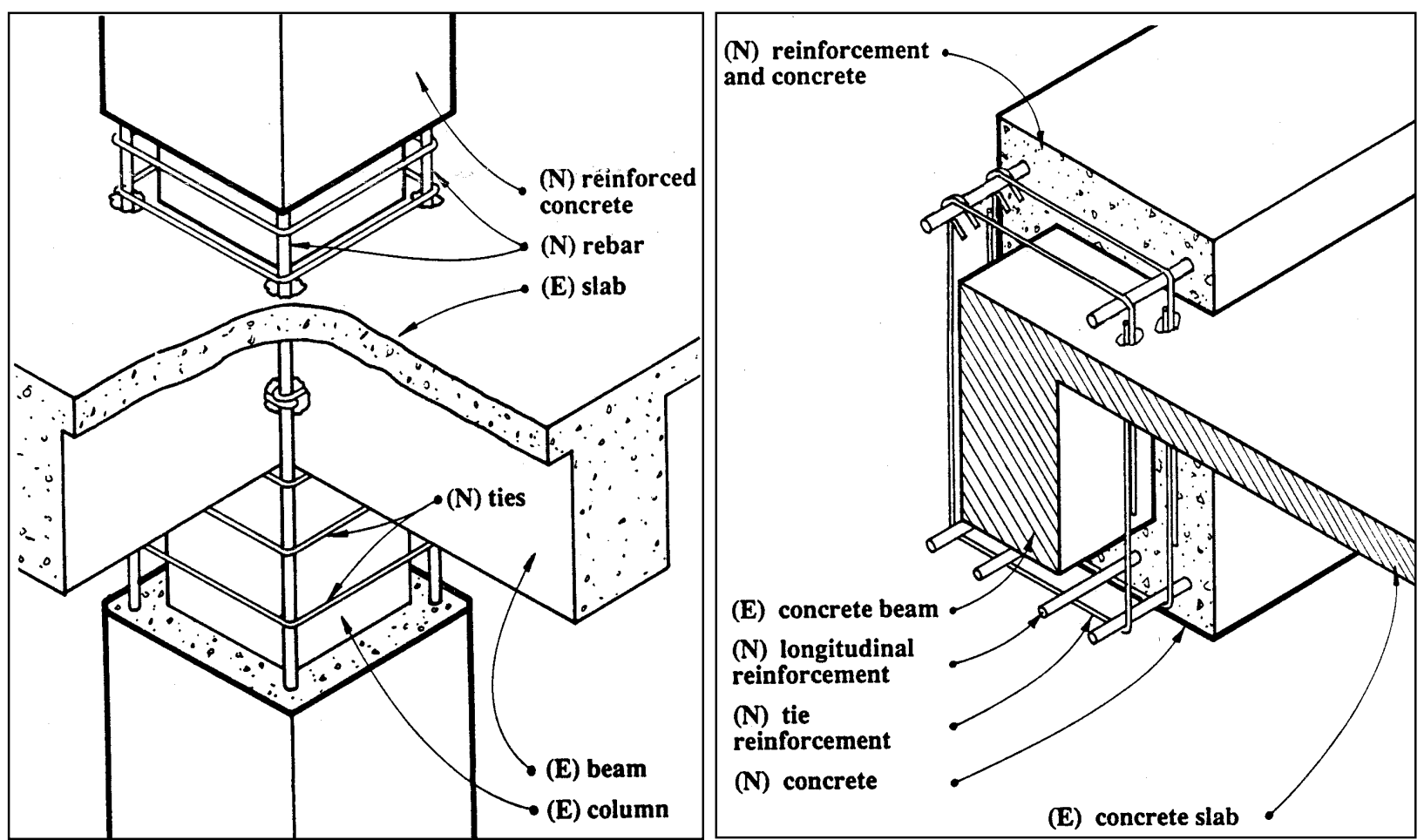

Fig. 7-Examples of seismic rehabilitation schemes given in FEMA 172: (left) column strengthening and (right) beam strengthening ( $E=$ existing and $N=$ new)

redundant steel columns).

FEMA 172, "NEHRP Handbook for Seismic Rehabilitation of Existing Buildings," provides conceptual illustrations of the various rehabilitation techniques (Fig. 7). The following categories for seismic strengthening are covered:

- Vertical resisting elements

- Moment frames

- Shear walls

- Braced frames

- Adding supplemental members

- Diaphragms

- Foundations

- Diaphragm to vertical element connections

- Vertical element to foundation connections

- New supplemental systems

Also covered are means to reduce seismic demand, such as:

- Reduce building mass

- Increase fundamental period

- Increase energy dissipation

- Seismic isolation

- Supplemental damping. 


\section{Approach to Seismic Rehabilitation (L. Wyllie)}

Approaching a seismic rehabilitation project is analogous to a "doctor-patient" relationship: first it is necessary to determine the "illness" and then chose the most appropriate "remedy." A major difference is the "cost" factor:(where it is often the controlling issue in seismic rehabilitation):

- Cost of removing and restoring finishes often exceeds cost of the structural modifications;

- Foundations are very expensive to modify;

- Usually the more economic solution is to add new elements to provide the needed strength and stiffness to protect the existing elements.

Seismic rehabilitation involves a global approach as opposed to concentrating on the lower stories, as is typical for ground level blast protection. Enhancing blast resistance involves consideration of different types of loads compared with seismic rehabilitation. 


\section{General Issues}

What do we mean by "collapse prevention" in a global sense? Emphasis in seismic research has been on lateral strength, but collapse prevention is an issue of vertical strength. In this respect, the blast community is ahead because the emphasis is on preventing vertical progressive collapse.

"Life safety:" versus "collapse prevention:"

- Life safety: no loss of life under likely events;

- Collapse prevention: no collapse under unlikely event

Blast loading is of such short duration that damping is not involved. In addition, the loading rates are high, and such rate-of-loading effects are important on the capacity side. Rate effects on the behavior of confined concrete are under investigation. Once these properties are understood, principles of structural engineering apply and seismic retrofit methods may be applied to progressive collapse prevention.

There is lack of communication among federal agencies with research programs on blast effects on buildings.

Results of single explosive tests are not useful to design engineers faced with different conditions than used for the tests. This is because these tests represent the response of a particular structure to a particular blast load. More cost-effective, dynamic testing is needed to allow an understanding of the effects of variations of design parameters on the response.

The GSA-developed interagency security criteria define levels of protection. Progressive collapse is a small part of the total security package. New construction requires design against progressive collapse. For existing construction, progressive collapse is considered only as part of other rehabilitation efforts, such as seismic retrofit. Most GSA buildings are in low seismic zones. The security criteria of the Interagency Security Committee (ISC) are being considered as a national standard. GSA progressive collapse criteria are based on the instantaneous removal of a primary vertical support (column or bearing wall), and require that this removal not result in progressive collapse of the structural bays directly affected by removal of the support. The collapse is limited to one bay on either side and one floor above where the support is removed.

UK approach to progressive collapse prevention is to provide adequate reinforcement detailing to tie structure together so that it can span across loss of support. This prescriptive approach is cost effective.

Issues related to use of FRP composites for strengthening:

- Durability;

- Structural fire performance;

- Quality control during installation;

- Consensus design standards

With regard to blast resistance and progressive collapse: 
- If column is hardened, is it necessary to also consider progressive collapse initiated by column removal?

- If column is hardened, other failure mechanisms need to be considered to ensure no progressive collapse; reinforcement details have to ensure that catenary action can be mobilized.

- Seismic retrofit methods used to enhance punching shear capacity, such as adding shear heads to columns, may be applicable to prevention of progressive collapse due to loss of slabcolumn connections.

Knowledge about out-of-plane strengthening of walls for seismic loading may be directly applicable to enhancing the blast resistance of walls. Strengthening methods may be used to enhance the ductility of walls and mitigate fragmentation. Any strategy needs to consider the load path to ensure that strengthening of one element does not result in a more hazardous failure mode.

Rehabilitation methodologies need to make use of basic engineering principles combined with the latest research findings. Competent engineers go beyond relying on code provisions to devise applicable retrofit methods. The same type of reliance on basic engineering and use of research findings are applicable to developing appropriate blast resistant retrofit measures. Knowledge of inelastic dynamic response for seismic design may be of value in blast resistant design.

There are few engineers with competence in blast-resistant design. A formal blast design standard is needed before it will be possible to increase the number of competent design professionals.

There is a need for an agency to collect and synthesize available information on the blast performance of structural and non-structural building elements. Federal agencies with interests in blast resistance and progressive collapse mitigation need to coordinate their activities to move toward a common goal to satisfy users' needs. 


\section{Conclusions}

It was the consensus of the participants that there is a need for a coordinated national effort to develop engineering tools to assist in designing structures to resist progressive collapse and to develop methods to rehabilitate structures that are vulnerable to progressive collapse. The latter effort would be analogous to those that have been developed for seismic rehabilitation under the NEHRP program.

The following short-term action plan was suggested:

1. Collect and synthesize available information on blast testing, performance prediction tools (modeling), and progressive collapse mitigation techniques to develop a clear assessment of what has been done, what is being done, what is being planned, and what should be done.

2. Assemble a high-level team to develop the framework for standards on blast-resistant design and retrofit of existing buildings and to mitigate progressive collapse. The objective is to identify knowledge gaps to direct subsequent research. Develop a draft national research plan.

3. Convene a workshop to refine the draft plan and develop a prioritized national research plan that could form the basis for a federally funded research program to support the development of design standards.

The objective of the research would be to develop the technical basis to allow the development of standards for blast-resistant design of new buildings and rehabilitation of existing building.

These standards would address progressive collapse analysis of existing structures and mitigation methods. 